AperTO - Archivio Istituzionale Open Access dell'Università di Torino

\title{
A Multicomponent Exercise Program for Older Adults Living in Residential Care Facilities: Direct and Indirect Effects on Physical Functioning
}

\section{This is the author's manuscript}

Original Citation:

Availability:

This version is available http://hdl.handle.net/2318/1506007

since 2016-01-12T13:13:02Z

Published version:

DOI:10.1123/japa.2013-0061

Terms of use:

Open Access

Anyone can freely access the full text of works made available as "Open Access". Works made available under a Creative Commons license can be used according to the terms and conditions of said license. Use of all other works requires consent of the right holder (author or publisher) if not exempted from copyright protection by the applicable law. 
This is the author's final version of the contribution published as:

Anna Mulasso;Mattia Roppolo;Monica Emma Liubicich;Michele Settanni;Emanuela Rabaglietti. A Multicomponent Exercise Program for Older Adults Living in Residential Care Facilities: Direct and Indirect Effects on Physical Functioning. JOURNAL OF AGING AND PHYSICAL

ACTIVITY. 23 (3) pp: 409-416.

DOI: 10.1123/japa.2013-0061

The publisher's version is available at:

http://journals.humankinetics.com/japa-back-issues/japa-volume-23-issue-3-july/a-multicomponent-exerciseprogram-for-older-adults-living-in-residential-care-facilitiesdirect-and-indirect-effects-on-physical-functioni ng

When citing, please refer to the published version.

Link to this full text:

http://hdl.handle.net/2318/1506007 


\title{
ORIGINAL RESEARCH
}

Mulasso et al.

Multicomponent Exercise Program Effects

http://dx.doi.org/10.1123/japa.2013-0061

Mulasso, Roppolo, and Rabaglietti are with the Department of Psychology, University of Torino, Torino, Italy; and the Motor Science Research Center, University School of Exercise and Sport Sciences, University of Torino, Torino, Italy. Liubicich is with the Motor Science Research Center, University School of Exercise and Sport Sciences, University of Torino, Torino, Italy. Settanni is with the Department of Psychology, University of Torino, Torino, Italy. Address author correspondence to Anna Mulasso at anna.mulasso@unito.it[AUQ1].

\section{A Multicomponent Exercise Program for Older Adults Living in Residential Care Facilities: Direct and Indirect Effects on Physical Functioning}

\author{
Anna Mulasso, Mattia Roppolo, Monica Emma Liubicich, Michele Settanni, and Emanuela Rabaglietti
}

\begin{abstract}
The aim of this study was to assess the direct and indirect effects of a multicomponent exercise (MCE) program on mobility and balance in institutionalized older people. One hundred and twelve subjects ( 85 women; 83.0 years on average; $S D=7.5$ ) were included in the study, and divided into a MCE-group (MCE-G) and a control group (CG) according to matching techniques. The MCE-G consisted of a 9-month program featuring range-of-motion, strength, and balance exercises performed in small groups. The $\mathrm{CG}$ received routine medical and nursing care. The timed up-and-go test and Tinetti Performance-Oriented Mobility Assessment balance subscale were administered at baseline and postintervention. After controlling for physical baseline value, age, sex, residential care facilities, and body mass index, the MCE-G showed positive effects both on mobility $(p<.001)$ and balance $(p=$ $.001)$. The role of balance as mediator in the relationship between participation to the MCE program and mobility was demonstrated.
\end{abstract}

Keywords: mobility, balance, institutionalized older adults, aged, mediation

Italy is one of the "oldest" countries in the world; in 2011, the country featured a $20 \%$ share of the [AUQ2] population aged over 60 (Eurostat, 2008). Italian women and men enjoy a life expectancy of 84 and 79 years, respectively. In Italy, the number of people aged over 65 will have grown by $70 \%$ by 2050 , and the number of the socalled "oldest-old" (people aged over 80) will grow by $170 \%$ (Eurostat, 2008). These trends will present consistent challenges in terms of health care demands and needs of the aging population. In fact, increase in age is associated with chronic diseases, dependency for carrying out the activities of daily living (ADL), disability, and institutionalization (World Health Organization [WHO], 2002).

There is unanimous agreement that regular physical exercise contributes to healthy aging (Chodzko-Zajko et al., 2009; Haskell et al., 2007; Nelson et al., 2007; Warburton, Nicol, \& Bredin, 2006; WHO, 2002). Several studies (Artaud et al., 2013; Avlund, Vass, \& Hendriksen, 2003; Penninx et al., 2001; van der Bij, Laurant, \& Wensing, 2002) identified physical inactivity as one of the most important risk factors for disability caused by chronic health problems, such as dementia, hypertension, diabetes mellitus, osteoporosis, obesity, and cardiovascular diseases.

Physical training can improve physical, cognitive, and psychological functioning of older adults. Clinical trials among community-dwelling older adults showed that regular physical exercise increases mobility (de Vries et al., 2012; Gill et al., 2004; Mulrow et al., 1994), balance (Miller, Magel, \& Hayes, 2010; Olson, Chen, \& Wang, 2011; Simons \& Andel, 2006), aerobic capacity (Buchner, Beresford, Larson, LaCroix, \& Wagner, 1992; xxxx et al., $\operatorname{xxxx}$ [AUQ3]), walking speed (Fiatarone et al., 1994; Taguchi,
Higaki, Inoue, Kimura, \& Tanaka, 2010), muscle strength (Cress et al., 1999; Lovell, Cuneo, \& Gass, 2010; Penninx et al., 2001), and muscle flexibility (Hallage et al., 2010), and also helps maintain a greater degree of autonomy. All these elements are closely related to a better perception of quality of life ([QOL]; Dechamps et al., 2010; Lobo, Santos, Carvalho, \& Mota, 2008). Limitations in physical functioning (i.e., mobility problems, balance impairments, decline in lower limb strength) are associated with higher risk of falls (Daley \& Spinks, 2000; Morita et al., 2005) and loss of autonomy for performing ADL (Cigolle, Langa, Kabeto, Tian, \& Blaum, 2007; Kempen \& Ormel, 1998).

So far, the evidence is limited and controversial regarding the benefits of physical exercise in older adults living in residential care facilities. Several studies (Bastone Ade \& Jacob Filho, 2004; Baum, Jarjoura, Polen, Faur, \& Rutecki, 2003; Cadore et al., 2014; Lazowski et al., 1999) reported increased physical performances in institutionalized older adults after a physical activity program. In particular, Cadore et al. (2014) showed enhanced mobility, balance, and strength performances with a reduced incidence of falls in frail nonagenarians after 12 weeks of multicomponent exercise. Bastone Ade and Jacob Filho (2004) found significant improvement in gait speed, strength, and lower limb function following six months of physical training (i.e., range of motion, strength, mobility exercises) in institutionalized older adults. Similarly, a randomized controlled trial (Baum et al., 2003) demonstrated that a 48-week program based on strength and flexibility exercises for frail older adults living in residential care facilities resulted in strong improvements in terms of mobility and a moderate increase in balance. In contrast, many studies

Page 1 of 10 
(Faber, Bosscher, Chin A Paw, \& van Wieringen, 2006; Mulrow et al., 1994; Nowalk, Prendergast, Bayles, D’Amico, \& Colvin, 2001) observed a weaker impact of physical training on institutionalized older adults. Mulrow et al. (1994) reported that, over four months, one-to-one sessions based on range of motion, strength, balance, transfer, and mobility exercises administered to frail residents in care facilities had no benefits on physical functioning, except for a modest increase in mobility. Likewise, Faber and colleagues (2006)[AUQ4] showed that frail older adults living in residential care facilities gained no benefit from moderate-intensity group exercise programs in terms of reduced risk of falling and physical performances, in contrast with prefrail condition subjects. Such contradictive findings might be attributable to the different extent and components of physical training programs. Thus, more research is needed to fill in such literature gaps (Rydwik, Frandin, \& Akner, 2004; Taguchi et al., 2010).

The purpose of the current study was to investigate the effects of a multicomponent exercise (MCE) program on the physical functioning of older adults living in residential care facilities. The specific aims were the following: (1) to determine the direct effects of physical training on mobility and balance and (2) to examine the indirect effects of balance on the relationship between participation in the physical intervention and mobility.

\section{Method}

\section{Participants}

A total of 581 subjects from six residential care facilities located in $\operatorname{xxxx} \operatorname{xxxx}$ [AUQ5] (xxxx) were assessed for eligibility; 387 did not meet the study's inclusion criteria and 82 did not participate for other reasons (i.e., lack of willingness, engagement in other activities). One hundred and twelve older adults, 27 men (24\%) and 85 women $(76 \%)$, were enrolled in the study. One hundred and four (93\%) subjects completed the study (Figure 1). Participants were included according to the following criteria: (a) they were aged over 65; (b) they could walk independently with or without assistive devices; (c) there were no contraindications to physical exercise (i.e., upper or lower extremity fractures or surgical operations within the previous 6 months); (d) participation was voluntary; (e) there was absence of serious diseases (i.e., dementia, Parkinson's disease, chronic obstructive pulmonary disease); and (f) they had been living in residential care facilities permanently, at least for one month.

\section{〈insert Figure $1 \backslash$}

\section{Procedure}

All the participants provided informed consent in accordance with $\operatorname{xxxx}$ [AUQ6] law and the $\operatorname{xxxx} \operatorname{xxxx[AUQ7]~ethical~code~}$ (xxxx[AUQ8], 1997).

Data were collected at baseline (T1) and postintervention (T2), nine months apart from each other. Both the evaluation sessions were conducted in the gym inside the residential care facility by qualified instructors trained in physical education and specialized in carrying out physical activity programs proper to older adults. The instructors administered physical tests, always in the same order and individually per each participant. During the physical test sessions, the residential care facility medical and nursing staff were always present, informed, and ready to intervene in case of adverse events. The evaluation sessions were carried out in the afternoon, at least $2 \mathrm{hr}$ after lunch.

Following the baseline assessment, the participants were divided in two groups, the multicomponent exercise group (MCE-G) or the control group (CG), according to sampling techniques that match pair samples and check on potential intervening variables (i.e., age, sex, physical functioning). To maintain the two groups (MCE-G and (G) as comparable as possible, the sample of participants was treated as a whole and the minimized randomization procedure was adopted.

The MCE-G took part in a nine-month MCE program, while the CG received routine medical and nursing care for the same amount of time. The participants of both groups were treated similarly except for the physical training and did not receive any incentives or reward for participating.

\section{Intervention}

The MCE program lasted 36 weeks and took place twice a week on nonconsecutive days; each session was $75 \mathrm{~min}$ and included alternating exercises in sitting and standing positions. In total, 68 sessions of the MCE program were carried out. The MCE program was performed in five groups, each made of 10-12 participants. The exercise sessions were led by an instructor trained in physical education and specialized in older adult adapted physical activity. All trainers received a detailed manual featuring the times and procedures pertaining to each exercise in order to standardize the intervention as much as possible. MCE sessions were carried out in spacious, bright, and warm lounge areas inside the residential care facilities, which could be easily reached by the participants.

According to recommendations from the American College of Sports Medicine and the American Heart Association (Nelson et al., 2007), every MCE session consisted of: (a) a warm-up phase (10 $\mathrm{min}$ ), including low-intensity exercises for major muscle masses in combination with breathing exercises; (b) range-of-motion training (20 min), based on exercises for neck, shoulders, wrists, hips, and ankles, to increase the movement range of joints and to improve motor coordination; (c) muscle-strengthening training (20 min), consisting of two exercises for upper limbs (arm curl, shoulder press) with increasing weights from 0.5 to $1.0 \mathrm{~kg}$, and two weight-bearing exercises for lower limbs (leg extension, hip flexion). Frequencies ranged from one set of 5-8 repetitions in the first training session to three sets of 10-12 repetitions at the end of the program. The choice of the initial load of $0.5 \mathrm{~kg}$ for the upper limb exercises was made to allow all participants to complete the whole set of repetitions; the weight progression was decided session by session on an individual level by the trainer. The muscle-strengthening exercises were selected for their similarity to basic everyday life activities (e.g., walking, climbing stairs, grasping objects) and their easy implementation. Additionally: (d) balance training (15 min), featuring exercises for static and dynamic balance; and (e) cool-down (10 min), based on flexibility exercises and physical games to foster socialization among participants.

In all MCE sessions, a stepwise approach was adopted. It was based on the gradual increase of training intensity and number of sets and repetitions, aimed at a progressive involvement of participants in a variety of different activities (Nelson et al., 2007; Pollock, Graves, Swart, \& Lowenthal, 1994) using both conventional (i.e., balls and little balls, circles, sticks) and unconventional instruments (i.e., bottles, scarves, paper tissues).

Residential care facility medical and nursing staff were always present, informed, and ready to intervene in case of adverse events during each training session. However, no adverse event occurred during the training program. 


\section{Measures}

\section{Physical Variables.}

To evaluate physical functioning, the following two standardized performance tests were administered.

The timed up-and-go test (TUG; Podsiadlo \& Richardson, 1991) was used to measure mobility in people who were able to walk on their own or with an assistive device. The instructor asked subjects to stand up from a chair, walk $3 \mathrm{~m}$, turn around a cone, walk back, and sit down. Timing started upon the instructor's "Go" and stopped when the subject returned to the initial position. The test was performed three times, in addition to an untimed trial. At least $2 \mathrm{~min}$ of rest occurred in between each trial. The best performance was used in the analysis. TUG is a reliable and valid instrument for quantifying functional mobility over time in older adults (Podsiadlo \& Richardson, 1991). Test-retest reliability ( $\mathrm{ICC}=.94$ in baseline and ICC $=.97$ in postintervention assessment) has been reported. These data confirmed the good reliability of the TUG, with ICC values comparable to other studies (Mesquita et al., 2013; Rockwood, Awalt, Carver, \& MacKnight, 2000; Steffen \& Seney, 2008). TUG values for healthy older adults (ranging from 80 to 99 years) are $11.3 \mathrm{~s}(10.0$ $12.7 \mathrm{~s}$ ) (Bohannon, 2006). As a rule, a TUG performance of less than $20 \mathrm{~s}$ is associated with independence in mobility, whereas a performance more than $30 \mathrm{~s}$ is associated with dependence (Podsiadlo \& Richardson, 1991).

The Tinetti Performance-Oriented Mobility Assessment balance subscale (POMA-B; Tinetti, 1986) was used for the evaluation of the balance component. POMA-B is among the most broadly-used measures in the study of balance dysfunctions in older adults (Pardasaney et al., 2012). It consists of nine items such as sitting balance, balance with eyes open/closed, and $360^{\circ}$ turning, evaluated on a $0-1$ or $0-2$ scale based on performance quality or on the use of assistive devices. The total score of the POMA-B ranges from 0 to 16 . The highest value corresponds to a higher performance. In previous studies, the balance subscale proved good reliability (.74; Faber, Bosscher, \& van Wieringen, 2006) and validity, with sensitivity and specificity values of .68 and .78, respectively (Harada et al., 1995). In the current study, the POMA-B appeared to have good internal consistency, with Cronbach's $\alpha$ values of .84 at baseline and .87 at the postintervention assessment (Nunnally \& Bernstein, 1994).

\section{Anthropometric Variables.}

Height was measured using an anthropometer, with a level of precision of $0.1 \mathrm{~cm}$. Weight was detected with the BF-350 Body Composition Analyzer (Tanita, Arlington Heights, IL), with a degree of precision of $0.1 \mathrm{~kg}$. The weight (in kilograms) divided by the square of height (in meters) provided the measure for body mass index (BMI).

\section{Statistical Analysis}

All the analyses were conducted with Statistical Package for Social Sciences (SPSS), version 20.0 (IBM, Chicago, IL). Statistical significance level was fixed at $p<.05$ for all tests.

First, descriptive and frequency analysis were computed for all the variables in the study. A $t$-test for unpaired samples and chisquare tests were performed to compare baseline demographic, anthropometric, and physical variables between groups. A one-way analysis of variance (ANOVA) was carried out to determine the site level comparability and the differences in subjects within and between sites, respectively. Given the employed sampling methodology, observations cannot be considered completely independent and consequently there exists the possibility of artificially small standard errors. To address this issue, intraclass correlation coefficients (ICCs) of the outcome variables were computed and all the analyses were carried out using the SPSS complex samples module, adjusting all standard errors and significance tests using the cluster information. The ICCs were computed as mean square between groups minus mean square within groups divided by the sum of mean square between groups and $(n-1)$ multiplied for mean square within groups.

To verify the MCE effect on physical functioning, an analysis of covariance (ANCOVA) per each dependent variable (mobility and balance) was conducted, with group (MCE-G vs. CG) as the independent variable, and baseline values of dependent variables including age, sex, and BMI as covariates. In addition, the effect size accounted by the MCE intervention was calculated with the Cohen's $d$ method (see Equation 1):

$$
D=\frac{\left(M_{M C E-G t 2}-M_{M C E-G t 1}\right)-\left(M_{C G t 2}-M_{C G t 1}\right)}{\sqrt{\frac{\left(N_{M C E-G}-1\right) \times S D_{M C E-G}^{2}+\left(N_{C G}-1\right) \times S D_{C G}^{2}}{N_{M C E-G}+N_{C G}-2}}}
$$

where MMCE-G and MCG are, respectively, the mean level for the MCE-G and the CG at baseline (T1) and postintervention (T2). $\mathrm{N}$ is the sample size for the two groups and $S D$ represents the standard deviation. According to the cut-off of Cohen (1988), the effect is small for $d<0.30$, medium for $d=0.30-0.80$, and large for $d>0.80$.

Lastly, to test the indirect effect of balance between participation in the MCE program and mobility, a mediation analysis was applied according to the product-of-coefficient approach (Cerin, 2010; Cerin \& Mackinnon, 2009). This method has been previously used to analyze mediating effects in physical exercise intervention studies (Haerens et al., 2008; xxxx, xxxx, xxxx, xxxx, \& $\mathrm{xxxx,}$ $\operatorname{xxxx}$ [AUQ9]). To perform the product-of-coefficient mediation, the following steps were executed: (1) $\alpha$ coefficient of mediation, regressing the posttest POMA-B scores on MCE and baseline POMA$\mathrm{B}$; (2) $\beta$ coefficient, regressing the posttest outcome scores (TUG) onto MCE, baseline outcome values, and pretest and postintervention POMA-B; (3) $\alpha \beta$ coefficient, multiplying the two previously cited regression coefficients; and (4) the $\mathrm{z}$ scores associated with the mediated effect dividing the $\alpha \beta$ coefficient by its standard error. $\alpha$ and $\beta$ coefficients are, respectively, a test for the action and the conceptual theory, used in mediation analyses (Cerin \& Mackinnon, 2009). Furthermore, $\tau$ ' coefficient, representing the unmediated intervention effects (used in Table 3 to assess the proportion of mediating effect), was computed.

Drop-outs $(n=8)$ were excluded from the analysis.

\section{Results}

\section{Baseline Characteristics}

Table 1 summarizes baseline characteristics of the MCE-G and the CG after attrition. The MCE-G and the CG were comparable at T1 for anthropometric and physical variables. BMI ranged from 14.7-43.8 $\mathrm{kg} / \mathrm{m}^{2}$, with a mean value of $26.0 \mathrm{~kg} / \mathrm{m}^{2}(S D=4.5)$. Subjects were classified as overweight according to clinical guidelines (National Institutes of Health, National Heart, Lung, and Blood Institute, 1998). Values of physical assessments (9.5/16.0 for POMA-B and 24.9 s for TUG) showed limitations in balance and mobility, with a consequent higher risk of falls.

As determined by one-way ANOVA, no difference was found among residential care facilities as far as mobility $(\mathrm{F}[5,105]=1.15, p$ 
$>.05)$ and balance $(\mathrm{F}[5,105]=1.21, p>.05)$. Moreover, subjects within and between sites reported no difference. For both outcomes, ICC were low, obtained by subtracting T2 from T1 $(r=.027$ for mobility, $r=.007$ for balance).

\section{〈insert Table $1 \backslash$}

\section{Adverse Events}

About $5 \%$ of the MCE-G $(n=3)$ and $9 \%$ of the CG $(n=5)$ dropped out from adverse events not related to study participation (Figure 1): illness (MCE-G: $n=2$; CG: $n=1$ ), hospitalization (MCE-G: $n=1$ ), transfer to other residential care facilities (CG: $n=2)$, and death (CG: $n=2$ ). No differences were found in terms of demographic, anthropometric, and physical variables between participants who completed the study and those who dropped out. Baseline homogeneity between the two groups was maintained after exclusion of drop-outs (Table 1).

\section{Adherence}

The average adherence (performed sessions of MCE divided by the total number of lessons) of the MCE-G members to the physical training was $84 \%(57 / 68)$, ranging from $76-100 \%$. Presence was counted only when the entire training session had been completed. Absences were due to health problems (8\%), medical examinations $(5 \%)$, and family visits $(3 \%)$. During the training sessions, no complications occurred (i.e., dizziness, exhaustion, muscle spasms) that prevented participation in the physical program. Thirty-eight subjects from the MCE-G continued the physical exercise training at the end of the study, and 22 of the CG members undertook a program of physical activity.

\section{Effects of Intervention}

The one-way ANCOVA showed a significant difference between the MCE-G and the CG as far as mobility $(\mathrm{F}[1,5]=202.45, p<.001)$, after having controlled the baseline value, age, sex, and BMI. The effect size was large $(d=0.81)$. In fact, between pre- and postintervention, the MCE-G improved mobility performances $(15 \%$, moving from $25.0-21.3 \mathrm{~s}$ ), whereas the CG performances decreased (16\%, moving from 24.8-29.6 s).

Similarly, after controlling the same covariates of the previous model, we found a statistically significant difference between the two groups in terms of balance (Wald $\mathrm{F}[1,97]=52.04, p=.001$ ), with a large effect size $(d=0.93)$. Between pre- and postintervention, balance increased in the MCE-G (from 9.7 to 12.0 , corresponding to $19 \%$ ) and decreased in the CG (from 9.2 to 8.4 , equal to $9 \%$ ) (see Table 2).

\section{〈insert Table 2〉}

\section{Mediation Model}

\section{Action Theory Test.}

The results of the action theory test are shown in Table $3(\alpha$ coefficient). The results have highlighted that the MCE program caused a significant increase in balance performance $(p<.001)$.

\section{〈insert Table $3 \backslash$}

\section{Conceptual Theory Test.}

The data presented in Table 3 ( $\beta$ coefficient) showed the significant relation between the POMA-B and the TUG, confirming the conceptual theory test. In particular, it is possible to observe a negative association between the mediator and the outcome $(p=.01)$.

\section{Mediated Effects.}

The model showed a statistically significant mediating effect (Table $3, \alpha \beta$ coefficient). The data revealed negative mediated effects of balance on mobility $(p<.001)$, meaning that a higher score on the POMA-B corresponded to a better TUG performance.

The mediated effect proportion was .40, corresponding to a medium-high proportion of mediation. In all the steps, statistically significant results were found.

\section{Discussion}

This study showed that a MCE program conducted twice a week by specifically-skilled staff improved mobility (15\%) and balance (19\%) performances of institutionalized older adults, with a large effect size of intervention. Conversely, the CG experienced loss of mobility $(16 \%)$ and worsening of balance $(9 \%)$.

The mean adherence of $84 \%$ reached in this study can be considered as a first indicator of intervention feasibility. It is high compared with other research having similar interventions and participants. Rydwik, Frandin, and Akner (2005) reported a mean adherence rate of $65 \%$ for a 10 -week physical training program; Bastone Ade and Jacob Filho (2004) reported a 68\% adherence rate for a six-month exercise program; Baum et al. (2003) reported an $80 \%$ adherence rate for one year of physical intervention.

Changes in mobility of $15 \%$ in the MCE-G were consistent with previous studies aimed to improve physical functioning in older adults (Justine, Hamid, Mohan, \& Jagannathan, 2012; Rydwik et al., 2005; Sauvage et al., 1992). More specifically, Lazowski et al. (1999) showed an improved mobility of $16 \%$ following the Functional Fitness for Long-Term Care Program based on strength, balance, flexibility, and walking exercises for a period of four months. An increased mobility of $15.5 \%$ resulted from a randomized controlled trial by Mulrow et al. (1994) based on one-to-one physical therapy interventions on range of motion, strength, balance, transfer, and mobility exercises.

Conversely, the $19 \%$ balance improvement obtained by the MCE-G is greater compared with the $9 \%$ obtained by Lazowski and colleagues (1999). Possible explanations could be ascribed to the longer period of training (nine months compared with four months), participants showing fewer physical impairments (being able to walk autonomously versus being able to stand with minimal assistance), and functional tests administered (POMA-B compared with the Berg Balance Scale) having different discriminating ability (Chiu, AuYeung, \& Lo, 2003). In contrast, Sauvage et al. (1992) and Schoenfelder (2000) did not find significant improvements in balance measures after a physical exercise program consisting of strengthening and aerobic exercises. Therefore, it is reasonable to state that a physical training program that is not specifically focused on balance exercises might limit the effect of the balance ability of older adults in residential care facilities. This hypothesis was supported by a previous randomized controlled trial (Gusi et al., 2012) that showed a significant increase in dynamic balance after the implementation of a specific balance training protocol in institutionalized older adults.

Results of this study, in accordance with those mentioned earlier, supported the greater effectiveness of a MCE intervention that stimulates different skills (i.e., balance, walking, range of motion, strength) in comparison with a single-component physical activity program. Further investigations will be needed to study the effects of 
dual-task training based on physical and cognitive activities in older adults living in residential care facilities.

As far as the indirect effects are concerned, the results of this study have demonstrated the mediation role of balance in the relationship between participation in the MCE program and mobility. The older adults who took part in the MCE intervention reported a greater level of mobility at the end of the training period, and this direct effect was mediated by the improvement of balance skills. Maintenance of a good level of mobility, tightly related to independence in ADL and QOL (Dirik, Cavlak, \& Akdag, 2006; Fagerstrom \& Borglin, 2010), should be a priority for older adults living in residential care facilities. Findings indicated that consequences of a MCE program in older adults are not always direct and linear. Specifically, the indirect effect of balance between participation in physical training and mobility should be carefully considered for the development and the implementation of future intervention studies in institutionalized older adults.

Our findings contribute to the awareness of how important physical exercise is in an aged population (Aoyagi \& Shephard, 2010; Chodzko-Zajko et al., 2009; Galloway \& Jokl, 2000; Nelson et al., 2007), demonstrating both direct and indirect effects in older adults living in residential care facilities.

There are several limitations to this study. The first is related to the selection of residential care facilities and participants; selection did not occur randomly, but on the basis of availability. However, the allocation of subjects to the MCE-G or CG was made through a minimized randomization procedure that allows the two groups to maintain as comparable as possible. This issue, in association with the small sample size, affected the power of the study, with statistical significance levels only for moderate effect size. Secondly, the residential care facilities involved in the study were located in a small area in $\operatorname{xxx}$ [AUQ10], making results impossible to be generalized to

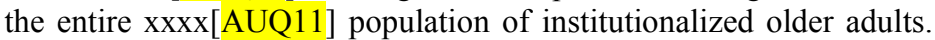
Thirdly, for reasons related to management and logistics of the residential care facilities, it was not possible to completely avoid "contamination" (i.e., separating older adults who took part in the intervention and those who were allocated in the CG). The subjects belonging to the two groups shared spaces and activities within the residential care facility; however, older adults of the CG did not participate at all in the physical training lessons but they had the possibility to join the program after the completion of the study. An additional limitation is related to the fact that no follow-up was carried out to evaluate maintenance of MCE training positive effects over time; this was not possible since many participants continued with the physical exercise. Furthermore, the preference for a battery of tests that were faster and easier to administer and the shortage of a broader evaluation of physical parameters (i.e., including strength, range of motion, flexibility evaluation) must be taken into account. Finally, the absence of a psychologist in half of the residential care facilities involved in the study did not allow for evaluation of the effects of the MCE on cognitive and psychological domains, which are strictly interconnected with physical functioning in older adults.

Further longitudinal investigations are needed. The involvement of residential care facilities spread throughout $\operatorname{xxxx}$ [AUQ12] territory, together with a more integrated multidomain assessment, will be needed to increase scientific knowledge on the benefits of exercise for older adults in residential care facilities.

\section{Conclusion}

The findings of this study suggest that older adults living in residential care facilities may benefit from a MCE program.
Furthermore, it provides the first scientific knowledge about the role of balance as a mediator in the relationship between participation in the MCE program and mobility.

\section{Acknowledgments}

This paper is in memory of professor $\operatorname{xxxx} \operatorname{xxxx}$ [AUQ13]: her fortitude and enthusiasm will always be with us. The authors would like to thank $\mathrm{xxxx}$ $\operatorname{xxxx}[$ AUQ14], $\mathrm{xxxx}$, and $\operatorname{xxxx} \operatorname{xxxx[AUQ15]~for~financial~support~to~the~}$ research program with the fellowship of Dr. $\operatorname{xxxx} \operatorname{xxxx[AUQ16].~Lastly,~a~}$ special thanks to the older people who took part in this study.

\section{References}

xxxx (1997). $x x x x$. Retrieved from xxxx [AUQ17]

Aoyagi, Y., \& Shephard, R.J. (2010). Habitual physical activity and health in the elderly: the Nakanojo Study. Geriatrics \& Gerontology International, 10(Suppl 1), S236-S243. PubMed

Artaud, F., Dugravot, A., Sabia, S., Singh-Manoux, A., Tzourio, C., \& Elbaz, A. (2013). Unhealthy behaviours and disability in older adults: three-city Dijon cohort study. BMJ (Clinical Research Ed.), 347, f4240. PubMed

Avlund, K., Vass, M., \& Hendriksen, C. (2003). Onset of mobility disability among community-dwelling old men and women. The role of tiredness in daily activities. Age and Ageing, 32(6), 579-584. PubMed doi:10.1093/ageing/afg101

Bastone Ade, C., \& Jacob Filho, W. (2004). Effect of an exercise program on functional performance of institutionalized elderly. Journal of Rehabilitation Research and Development, 41(5), 659-668. PubMed doi:10.1682/JRRD.2003.01.0014

Baum, E.E., Jarjoura, D., Polen, A.E., Faur, D., \& Rutecki, G. (2003). Effectiveness of a group exercise program in a long-term care facility: a randomized pilot trial. Journal of the American Medical Directors Association, 4(2), 74-80. PubMed doi:10.1016/S1525-8610(04)70279-0

Bohannon, R.W. (2006). Reference values for the timed up and go test: a descriptive meta-analysis. Journal of Geriatric Physical Therapy, 29(2), 64-68. PubMed doi:10.1519/00139143-200608000-00004

Buchner, D.M., Beresford, S.A., Larson, E.B., LaCroix, A.Z., \& Wagner, E.H. (1992). Effects of physical activity on health status in older adults. II. Intervention studies. Annual Review of Public Health, 13, 469-488. PubMed

Cadore, E.L., Casas-Herrero, A., Zambom-Ferraresi, F., Idoate, F., Millor, N., Gómez, M., . . .Izquierdo, M. (2014). Multicomponent exercises including muscle power training enhance muscle mass, power output, and functional outcomes in institutionalized frail nonagenarians. Age, 36, 773-785. PubMed

Cerin, E. (2010). Ways of unraveling how and why physical activity influences mental health through statistical mediation analyses. Mental Health and Physical Activity, 3(2), 51-60. doi:10.1016/j.mhpa.2010.06.002

Cerin, E., \& Mackinnon, D.P. (2009). A commentary on current practice in mediating variable analyses in behavioural nutrition and physical activity. Public Health Nutrition, 12(8), 1182-1188. PubMed

Chiu, A.Y., Au-Yeung, S.S., \& Lo, S.K. (2003). A comparison of four functional tests in discriminating fallers from non-fallers in older people. Disability and Rehabilitation, 25(1), 45-50. PubMed

Chodzko-Zajko, W.J., Proctor, D.N., Fiatarone Singh, M.A., Minson, C.T., Nigg, C.R., Salem, G.J., . . A American College of Sports Medicine. (2009). American College of Sports Medicine position stand. Exercise and physical activity for 
older adults. Medicine and Science in Sports and Exercise, 41(7), 1510-1530. PubMed doi:10.1249/MSS.0b013e3181a0c95c

Cigolle, C.T., Langa, K.M., Kabeto, M.U., Tian, Z., \& Blaum, C.S. (2007). Geriatric conditions and disability: the Health and Retirement Study. Annals of Internal Medicine, 147(3), 156-164. PubMed doi:10.7326/0003-4819-147-3200708070-00004

Cohen, J. (1988). Statistical power analysis for the behavioral sciences. Denmark: L. Erlbaum Associates.

Cress, M.E., Buchner, D.M., Questad, K.A., Esselman, P.C., deLateur, B.J., \& Schwartz, R.S. (1999). Exercise: effects on physical functional performance in independent older adults. The Journals of Gerontology. Series A, Biological Sciences and Medical Sciences, 54(5), M242-M248. PubMed doi:10.1093/gerona/54.5.M242

Daley, M.J., \& Spinks, W.L. (2000). Exercise, mobility and aging. Sports Medicine (Auckland, N.Z.), 29(1), 1-12. PubMed doi:10.2165/00007256-200029010-00001

de Vries, N.M., Van Ravensberg, C.D., Hobbelen, J.S.M., Olde Rikkert, M.G.M., Staal, J.B., \& Nijhuis-van der Sanden, M.W.G. (2012). Effects of physical exercise therapy on mobility, physical functioning, physical activity and quality of life in community-dwelling older adults with impaired mobility, physical disability and/or multi-morbidity: a meta-analysis. Ageing Research Reviews, 11(1), 136-149. PubMed doi:10.1016/j.arr.2011.11.002

Dechamps, A., Diolez, P., Thiaudiere, E., Tulon, A., Onifade, C., Vuong, T., . . . Bourdel-Marchasson, I. (2010). Effects of exercise programs to prevent decline in health-related quality of life in highly deconditioned institutionalized elderly persons: a randomized controlled trial. Archives of Internal Medicine, 170(2), 162-169. PubMed

Dirik, A., Cavlak, U., \& Akdag, B. (2006). Identifying the relationship among mental status, functional independence and mobility level in Turkish institutionalized elderly: gender differences. Archives of Gerontology and Geriatrics, 42(3), 339350. PubMed

Eurostat. (2008). Population projections 2008-2060. (119/2008). Luxemburg.

Faber, M.J., Bosscher, R.J., Chin A Paw, M.J., \& van Wieringen, P.C. (2006). Effects of exercise programs on falls and mobility in frail and pre-frail older adults: a multicenter randomized controlled trial. Archives of Physical Medicine and Rehabilitation, 87(7), 885-896. doi:10.1016/j.apmr.2006.04.005

Faber, M.J., Bosscher, R.J., \& van Wieringen, P.C. (2006). Clinimetric properties of the performance-oriented mobility assessment. Physical Therapy, 86(7), 944-954. PubMed

Fagerstrom, C., \& Borglin, G. (2010). Mobility, functional ability and health-related quality of life among people of 60 years or older. Aging Clinical and Experimental Research, 22(5-6), 387394. PubMed

Fiatarone, M.A., O’Neill, E.F., Ryan, N.D., Clements, K.M., Solares, G.R., Nelson, M.E., . . .Evans, W.J. (1994). Exercise training and nutritional supplementation for physical frailty in very elderly people. The New England Journal of Medicine, 330(25), 1769-1775. PubMed doi:10.1056/NEJM199406233302501

Galloway, M.T., \& Jokl, P. (2000). Aging successfully: the importance of physical activity in maintaining health and function. The Journal of the American Academy of Orthopaedic Surgeons, 8(1), 37-44. PubMed

Gill, T.M., Baker, D.I., Gottschalk, M., Peduzzi, P.N., Allore, H., \& Van Ness, P.H. (2004). A prehabilitation program for the prevention of functional decline: effect on higher-level physical function. Archives of Physical Medicine and Rehabilitation, 85(7), 1043-1049. PubMed

Gusi, N., Carmelo Adsuar, J., Corzo, H., Del Pozo-Cruz, B., Olivares, P.R., \& Parraca, J.A. (2012). Balance training reduces fear of falling and improves dynamic balance and isometric strength in institutionalised older people: a randomised trial. Journal of Physiotherapy, 58(2), 97-104. PubMed

Haerens, L., Cerin, E., Maes, L., Cardon, G., Deforche, B., \& De Bourdeaudhuij, I. (2008). Explaining the effect of a 1-year intervention promoting physical activity in middle schools: a mediation analysis. Public Health Nutrition, 11(5), 501-512. PubMed

Hallage, T., Krause, M.P., Haile, L., Miculis, C.P., Nagle, E.F., Reis, R.S., Da Silva, S.G. (2010). The effects of 12 weeks of step aerobics training on functional fitness of elderly women. Journal of Strength and Conditioning Research, 24(8), 2261-2266. PubMed doi:10.1519/JSC.0b013e3181ddacc6

Harada, N., Chiu, V., Damron-Rodriguez, J., Fowler, E., Siu, A., \& Reuben, D.B. (1995). Screening for balance and mobility impairment in elderly individuals living in residential care facilities. Physical Therapy, 75(6), 462-469. PubMed

Haskell, W.L., Lee, I., Pate, R.R., Powell, K.E., Blair, S.N., Franklin, B.A., . . . Bauman, A. (2007). Physical activity and public health: updated recommendation for adults from the American College of Sports Medicine and the American Heart Association. Medicine and Science in Sports and Exercise, 39(8), 1423-1434. doi:10.1249/mss.0b013e3180616b27

Jones, C.J., \& Rose, D.J. (2005). Physical activity instruction of older adults. Champaign, IL: Human Kinetics. [AUQ18]

Justine, M., Hamid, T.A., Mohan, V., \& Jagannathan, M. (2012). Effects of multicomponent exercise training on physical functioning among institutionalized elderly. International Scholarly Research Notices, Rehabilitation, 2012, article ID 124916.

Kempen, G.I., \& Ormel, J. (1998). The impact of physical performance and cognitive status on subsequent ADL disability in low-functioning older adults. International Journal of Geriatric Psychiatry, 13(7), 480-483. PubMed doi:10.1002/(SICI)1099-1166(199807)13:7<480::AIDGPS805>3.0.CO;2-S

Lazowski, D.A., Ecclestone, N.A., Myers, A.M., Paterson, D.H., Tudor-Locke, C., Fitzgerald, C., . . .Cunningham, D.A. (1999). A randomized outcome evaluation of group exercise programs in long-term care institutions. The Journals of Gerontology. Series A, Biological Sciences and Medical Sciences, 54(12), M621-M628. PubMed doi:10.1093/gerona/54.12.M621

Lobo, A., Santos, P., Carvalho, J., \& Mota, J. (2008). Relationship between intensity of physical activity and health-related quality of life in Portuguese institutionalized elderly. Geriatric \& Gerontology International, 8(4), 284-290. PubMed

Lovell, D.I., Cuneo, R., \& Gass, G.C. (2010). Can aerobic training improve muscle strength and power in older men? Journal of Aging and Physical Activity, 18(1), 14-26. PubMed

Mesquita, R., Janssen, D.J., Wouters, E.F., Schols, J.M., Pitta, F., \& Spruit, M.A. (2013). Within-day test-retest reliability of the timed up \& go test in patients with advanced chronic organ failure. Archives of Physical Medicine \& Rehabilitation, 94, 2131-2138. PubMed

Miller, K.L., Magel, J.R., \& Hayes, J.G. (2010). The effects of a home-based exercise program on balance confidence, 
balance performance, and gait in debilitated, ambulatory community-dwelling older adults: a pilot study. Journal of Geriatric Physical Therapy, 33(2), 85-91. PubMed

Morita, M., Takamura, N., Kusano, Y., Abe, Y., Moji, K., Takemoto, T., Aoyagi, K. (2005). Relationship between falls and physical performance measures among community-dwelling elderly women in Japan. Aging Clinical Experimental Research, 17(3), 211-216. PubMed

Mulrow, C.D., Gerety, M.B., Kanten, D., Cornell, J.E., DeNino, L.A., Chiodo, L., . . .Solis, R.M. (1994). A randomized trial of physical rehabilitation for very frail nursing home residents. Journal of the American Medical Association, 271(7), 519-524. PubMed doi:10.1001/jama.1994.03510310049037

National Institutes of Health, National Heart, Lung, and Blood Institute. (1998). Clinical Guidelines on the identification, evaluation and treatment of overweight and obesity in adults (pp. 1-226).

Available: http://www.nhlbi.nih.gov/files/docs/guidelines/ob gdlns.pdf.

Nelson, M.E., Rejeski, W.J., Blair, S.N., Duncan, P.W., Judge, J.O., King, A.C., . . .Castaneda-Sceppa, C. (2007). Physical activity and public health in older adults: recommendation from the American College of Sports Medicine and the American Heart Association. Medicine and Science in Sports and Exercise, 39(8), 1435-1445. PubMed doi:10.1249/mss.0b013e3180616aa2

Nowalk, M.P., Prendergast, J.M., Bayles, C.M., D’Amico, F.J., \& Colvin, G.C. (2001). A randomized trial of exercise programs among older individuals living in two long-term care facilities: the FallsFREE Program. Journal of the American Geriatrics Society, 49(7), 859-865. PubMed doi:10.1046/j.1532-5415.2001.49174.x

Nunnally, J.C., \& Bernstein, I.H. (1994). Psychometric theory (3rd ed.). New York, NY: McGraw-Hill.

Olson, S.L., Chen, S.S., \& Wang, C.Y. (2011). Effect of a home exercise program on dynamic balance in elderly with a history of falls. Journal of Aging and Physical Activity, 19(4), 291-305. PubMed

Pardasaney, P.K., Latham, N.K., Jette, A.M., Wagenaar, R.C., Ni, P., Slavin, M.D., Bean, J.F. (2012). Sensitivity to change and responsiveness of four balance measures for community-dwelling older adults. Physical Therapy, 92(3), 388-397. PubMed

Penninx, B.W., Messier, S.P., Rejeski, W.J., Williamson, J.D., DiBari, M., Cavazzini, C., .. . Pahor, M. (2001). Physical exercise and the prevention of disability in activities of daily living in older persons with osteoarthritis. Archives of Internal Medicine, 161(19), 2309-2316. PubMed

Podsiadlo, D., \& Richardson, S. (1991). The timed "Up \& Go": a test of basic functional mobility for frail elderly persons. Journal of the American Geriatrics Society, 39(2), 142-148. PubMed doi:10.1111/j.1532-5415.1991.tb01616.x

Pollock, M.L., Graves, J.E., Swart, D.L., \& Lowenthal, D.T. (1994). Exercise training and prescription for the elderly. Southern Medical Journal, 87(5), S88-S95. PubMed doi:10.1097/00007611-199405000-00017

Rockwood, K., Awalt, E., Carver, D., \& MacKnight, C. (2000). Feasibility and measurement properties of the functional reach and the timed up and go tests in the Canadian study of health and aging. The Journals of Gerontology. Series A,
Biological Sciences and Medical Sciences, 55(2), M70M73. PubMed doi:10.1093/gerona/55.2.M70

xxxx, xxxx, $\mathrm{xxxx}, \mathrm{xxxx}, \mathrm{xxxx}, \mathrm{xxxx}, \mathrm{xxxx}, \mathrm{xxxx}, \& \mathrm{xxxx}, \mathrm{xxxx}$.

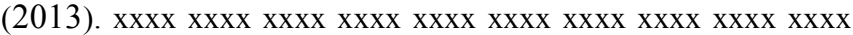

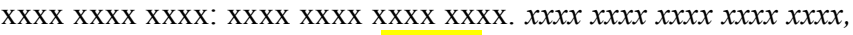
$\operatorname{xxxx}(\mathrm{xxxx}), \mathrm{xxxx}$. doi: $\mathrm{xxxx}$ [AUQ19]

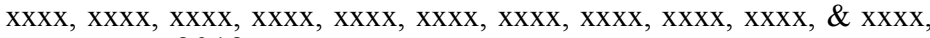
xxxx. (2012). Xxxx Xxxx Xxxx Xxxx: Xxxx xxxx Xxxx Xxxx xxxx Xxxx $\quad$ Xxxx $\quad$ xxxx. $x x x x \quad x x x x \quad x x x x \quad x x x x, \quad x x x x(\mathrm{xxxx}), \quad \mathrm{xxxx}$. doi: $\operatorname{xxxx}$ [AUQ20]

Rydwik, E., Frandin, K., \& Akner, G. (2004). Effects of physical training on physical performance in institutionalised elderly patients $(70+)$ with multiple diagnoses. Age and Ageing, 33(1), 13-23. PubMed doi:10.1093/ageing/afh001

Rydwik, E., Frandin, K., \& Akner, G. (2005). Physical training in institutionalized elderly people with multiple diagnoses-a controlled pilot study. Archives of Gerontology and Geriatrics, 40(1), 29-44. PubMed

Sauvage, L.R., Jr., Myklebust, B.M., Crow-Pan, J., Novak, S., Millington, P., Hoffman, M.D., . . .Rudman, D. (1992). A clinical trial of strengthening and aerobic exercise to improve gait and balance in elderly male nursing home residents. American Journal of Physical Medicine \& Rehabilitation, 71(6), 333-342. doi:10.1097/00002060-199212000-00005

Schoenfelder, D.P. (2000). A fall prevention program for elderly individuals. Exercise in long-term care settings. Journal of Gerontological Nursing, 26(3), 43-51. $\quad$ PubMed doi:10.3928/0098-9134-20000301-09

Simons, R., \& Andel, R. (2006). The effects of resistance training and walking on functional fitness in advanced old age. Journal of Aging and Health, 18(1), 91-105. PubMed doi:10.1177/0898264305281102

Steffen, T., \& Seney, M. (2008). Test-retest reliability and minimal detectable change on balance and ambulation tests, the 36-item short-form health survey, and the unified Parkinson disease rating scale in people with parkinsonism. Physical Therapy, 88(6), 733746. PubMed

Taguchi, N., Higaki, Y., Inoue, S., Kimura, H., \& Tanaka, K. (2010). Effects of a 12-month multicomponent exercise program on physical performance, daily physical activity, and quality of life in very elderly people with minor disabilities: an intervention study. Journal of Epidemiology, 20(1), 21-29. PubMed

Tinetti, M.E. (1986). Performance-oriented assessment of mobility problems in elderly patients. Journal of the American Geriatrics Society, 34(2), 119-126. PubMed doi:10.1111/j.1532-5415.1986.tb05480.x

van der Bij, A.K., Laurant, M.G., \& Wensing, M. (2002). Effectiveness of physical activity interventions for older adults: a review. American Journal of Preventative Medicine, 22(2), 120133. PubMed

Warburton, D.E., Nicol, C.W., \& Bredin, S.S. (2006). Health benefits of physical activity: the evidence. Canadian Medical Association Journal, 174(6), 801-809. PubMed doi:10.1503/cmaj.051351

World Health Organization (WHO). (2002). Active Ageing: a policy framework. Madrid, Spain: World Health Organization.

Figure 1 - The consort flow chart. 
Table 1 Baseline Characteristics of Participants (After Attrition $N=104$ )

\begin{tabular}{|c|c|c|c|}
\hline Variable & MCE-G $(n=53)$ & $\mathrm{CG}(n=51)$ & $P$-value \\
\hline Age, mean $(S D)$ & $83.0(7.5)$ & $83.0(7.0)$ & $.89^{\ddagger}$ \\
\hline \multicolumn{4}{|l|}{ Sex, n (\%) } \\
\hline Female & $42(79)$ & $39(76)$ & .92 \\
\hline Male & $11(21)$ & $12(24)$ & \\
\hline \multicolumn{4}{|l|}{ Marital status, n (\%) } \\
\hline Never married & $11(21)$ & $18(35)$ & \\
\hline Married & $5(9)$ & $6(12)$ & .37 \\
\hline Widowed & $36(68)$ & $27(53)$ & \\
\hline Divorced & $1(2)$ & - & \\
\hline \multicolumn{4}{|l|}{ Level of education, $n(\%)$} \\
\hline Primary school & $27(51)$ & $21(41)$ & $.38^{\ddagger}$ \\
\hline More than primary school & $26(49)$ & $30(59)$ & \\
\hline \multicolumn{4}{|l|}{ Original region, n (\%) } \\
\hline xxxx xxxx[AUQ21] & $39(74)$ & $31(61)$ & \\
\hline $\operatorname{xxxx} \operatorname{xxxx}$ & $5(10)$ & $9(18)$ & .32 \\
\hline $\mathrm{xxxx} \mathrm{xxxx}$ & $8(14)$ & $11(21)$ & \\
\hline Foreign countries & $1(2)$ & - & \\
\hline \multicolumn{4}{|l|}{ Past job, n (\%) } \\
\hline Manual & $41(78)$ & $44(86)$ & .28 \\
\hline Nonmanual & $12(22)$ & $7(14)$ & \\
\hline BMI, $\mathrm{kg} / \mathrm{m}^{2}$, mean $(S D)$ & $26.3(5.2)$ & $25.6(3.6)$ & $.65^{\dagger}$ \\
\hline TUG, seconds, mean ( $S D)$ & $25.0(10.3)$ & $24.8(9.6)$ & $.94^{\dagger}$ \\
\hline POMA-B, mean $(S D)$ & $9.7(3.4)$ & $9.2(3.6)$ & $.73^{\dagger}$ \\
\hline
\end{tabular}

Abbreviations: $\mathrm{BMI}=$ body mass index (computed as weight divided by squared height $\left[\mathrm{kg} / \mathrm{m}^{2}\right]$ ); TUG $=$ timed up-and-go test; POMA-B $=$ Performance-Oriented Mobility Assessment balance subscale; $\mathrm{MCE}-\mathrm{G}=$ multicomponent exercise group; $\mathrm{CG}=$ control group.

${ }^{\dagger}$ Based on value of $t$ test for unpaired samples.

$\star$ Based on value of likelihood ratio chi-square statistic with the Rao-Scott’s correction for complex sampling.

Table 2 Analysis of Covariance: Effects of Intervention

\begin{tabular}{|c|c|c|c|c|c|c|c|}
\hline & \multicolumn{4}{|c|}{ Group } & \multirow[b]{3}{*}{ Wald F } & \multirow[b]{3}{*}{$p$} & \multirow[b]{3}{*}{ Effect Size } \\
\hline & \multicolumn{2}{|c|}{ MCE-G } & \multicolumn{2}{|c|}{$C G$} & & & \\
\hline & $\begin{array}{l}\text { Baseline } \\
\mathrm{M}(S D)\end{array}$ & $\begin{array}{c}\text { Postintervention } \\
\qquad \mathrm{M}(S D)\end{array}$ & $\begin{array}{l}\text { Baseline } \\
\mathrm{M}(S D)\end{array}$ & $\begin{array}{c}\text { Postintervention } \\
\qquad \mathrm{M}(S D)\end{array}$ & & & \\
\hline TUG (s) & $25.0(10.3)$ & $21.3(9.1)$ & $24.8(9.6)$ & $29.6(11.5)$ & 202.45 & $<.001$ & 0.81 \\
\hline POMA-B & $9.7(3.4)$ & $12.0(2.8)$ & $9.2(3.6)$ & $8.4(3.5)$ & 52.04 & .001 & 0.93 \\
\hline
\end{tabular}

Abbreviations: TUG = timed up-and-go test; POMA-B = Performance-Oriented Mobility Assessment balance subscale; $\mathrm{MCE}-\mathrm{G}=$ multicomponent exercise group; CG = control group.

Table 3 Mediation Effects of Changes in POMA-B on TUG

\begin{tabular}{ccccccc}
\hline & \multicolumn{7}{c}{ Single Mediator Model on TUG (s) } \\
\cline { 2 - 7 } Mediator & $\alpha(S E)$ & $\beta(S E)$ & $\alpha \beta(S E)$ & $95 \%$ Cl of $\alpha \beta$ & z & $\alpha \beta /\left(\alpha \beta+\tau^{\prime}\right)$ \\
\hline POMA-B & $3.35(.50)^{*}$ & $-1.59(.41)^{*}$ & $-5.33(1.59)^{*}$ & -8.45 to -2.21 & -3.35 & .40 \\
\hline
\end{tabular}

Abbreviations: POMA-B = Performance-Oriented Mobility Assessment balance subscale; TUG = timed up-and-go test; $\alpha=$ estimate of intervention effect (unstandardized regression coefficient) on score of POMA-B; $\beta=$ estimate of the independent effect of the mediator (unstandardized regression coefficient) on scores of TUG (s); $\alpha \beta=$ product of coefficient estimate, mediated effect; $95 \%$ CI of $\alpha \beta=95 \%$ confidence interval of the mediated effect; $z=$ standard deviated associated with mediated effect (used for significance testing); $\alpha \beta /\left(\alpha \beta+\tau^{\prime}\right)=$ proportion of mediated effect; $S E=$ standard error.

$* p<.05$. 


\section{Author Queries}

[AUQ1] Ensure author bios are accurate.

[AUQ2] Of the world population? Or 20\% of Italy was over age $60 ?$

[AUQ3] Update reference.

[AUQ4] The citation "Faber and colleagues (2006)" matches multiple references. Please add the second author here to differentiate.

[AUQ5] Please update.

[AUQ6] Update.

[AUQ7] Update.

[AUQ8] Update.

[AUQ9] Update.

[AUQ10] Update.

[AUQ11] Update.

[AUQ12] Update.

[AUQ13] Update.

[AUQ14] Update.

[AUQ15] Update.

[AUQ16] Update. 
[AUQ17] Update.

[AUQ18] Reference "Jones, 2005" is not cited in the text. Please add an in-text citation or delete the reference.

[AUQ19] Update.

[AUQ20] Update.

[AUQ21] Update. 